\title{
Organizing Creativity for Innovation: Situated Practices and Process Perspectives
}

\author{
Elke Schüßler $^{1}$, Silviya Svejenova ${ }^{2}$, Patrick Cohendet ${ }^{3}$
}

Forthcoming in: Schuessler, Elke/Cohendet, Patrick/Svejenova, Silviya (2021): Organizing Creativity in the Innovation Journey (Research in the Sociology of Organizations Volume 75; p. 1-16)

\footnotetext{
${ }^{1}$ Johannes Kepler University; elke.schuessler@jku.at

${ }^{2}$ Copenhagen Business School

${ }^{3}$ HEC Montreal
} 


\begin{abstract}
:
This volume brings together empirical and conceptual papers that investigate the challenges of organizing creativity in the innovation journey in and across different empirical contexts. Seen as the basis for innovating new products, processes or services, organizing creativity is investigated as intentional efforts that occur in teams, organizations, and fields. What creativity is, how it is defined, negotiated and recognized is hereby co-constructed with different audiences and in different economic and societal spheres. The articles in this volume extend our understanding of these contextualized social dynamics of organizing creativity in four directions. The first direction sheds light on the temporal dynamics of organizing creativity in artistic fields. The second direction compares creative processes in arts and science, thereby examining tensions and uncertainties in the creative process unfolding in two distinctive contexts of creativity. The third direction investigates identity struggles of creative agents in organizations with clashing roles, professional norms, and ambiguities in creativity assessment. The fourth and final direction unravels the communicative journey of ideas from pitching to feedback, revealing how ideas are challenged, enriched, and acquire meaning in communicative interaction. Overall, the articles in this volume contribute to a situated view of creative processes in innovation which goes beyond questions of idea generation to account for dynamics of idea development, judgement, and dissemination which involve identity struggles, evaluation, and communication - processes which are at the heart of organizing for innovation.
\end{abstract}

\title{
Acknowledgements
}

We thank the German Research Foundation (DFG) for providing funding for this research, including for the organization of the international conference "Organizing Creativity in the Innovation Journey" held at Freie Universität Berlin in July 2019 where a number of articles in this volume were presented. Other articles were presented at Subtheme "Shedding Light on the Dark Sides of Creativity and Innovation" of the 35th EGOS Colloquium in Edinburgh co-organized by Birke Otto, Oliver Ibert and Elke Schüßler. We are grateful to Joerg Sydow for comments on earlier drafts and for heading the DFG Research Unit "Organized Creativity", which provided a fruitful environment for this volume to develop. Silviya Svejenova gratefully acknowledges funding from the Velux Foundation (Velux Project \#00021807 "The Temporality of Innovation") for her work on this volume and introduction. Thanks also go to René Haas for help with formatting and administration, and to all the reviewers for their generous and constructive comments. 


\section{THE IMPORTANCE OF ORGANIZING CREATIVITY FOR INNOVATION}

The global coronavirus pandemic, which is ongoing at the time this volume goes into print, has significantly challenged our extant ways of living and working, as well as shattered lives, employment opportunities, businesses, and communities. Yet, it has also raised renewed calls from different quarters - from international aid institutions through business leaders to academics - for creativity and innovation that can provide novel crisis and post-crisis solutions that enable community resilience, sustainable businesses, and personal coping and well-being. Some examples of such crisis-driven creativity and innovation approaches include new digital forms of artistic creativity, albeit amidst an acute precarity in the arts sector, severely affected by the pandemic lockdowns; the immense and unprecedentedly fast-paced scientific creativity that has brought vaccines in record time, though drawing undoubtedly on decades-long research, development, and innovation; the frugal creativity and innovation in overwhelmed hospitals struggling to save lives with limited resources; organizations' resourcefulness in reimagining themselves to endure the crisis, and not least people's everyday creativity in helping each other and making do in the community. These are only some examples of the organizing power of creativity.

Yet, creativity has been "in" long before the pandemic, acknowledged as predominantly positive and desirable force by the academic community and managerial practice alike. Scholars in a range of disciplines such as psychology (Hennessey \& Amabile, 2010), economics (Menger, 2014), sociology (Goddart, Seong, \& Phillips, 2020), and organization studies (George, 2007; Woodman, Sawyer, \& Griffin, 1993) have sought to define it as a distinct field of study within their respective knowledge domains, synthesizing extant contributions, providing empirical evidence, and charting directions for further investigation. Commonly understood as the generation of novel and potentially valuable ideas (Amabile, 1988), creativity has been recognized for its value-creating role not only in artistic and aesthetic endeavors (DeFillippi, Grabher, \& Jones, 2007; Galenson, 2007), but also in a variety of organizational and social contexts (Amabile, 1996) as well as in everyday action (Joas, 1996). Critical voices have pointed to a general creativity imperative in a society of "singularities" marked by an ongoing quest for novelty and surprise (Reckwitz, 2017). They have argued that creativity is "a wellbehaved category and phenomenon" in the context of a "dominant neoliberal, market-focused ideology of "creativity" in service of progress and growth (Rehn \& De Cock, 2009: 223).

As part of this hype, creativity has been found essential and useful for innovation processes in all sectors of the economy and society (Mann \& Chan, 2011). Yet, innovation research has often reduced the significance of creativity to the initial stage of idea generation in complex innovation processes, reserving for innovation "the subsequent stage of implementing ideas toward better procedures, practices, or products" (Anderson et al. 2014: 1298), despite recognizing that the realm between the two is a grey area (Gilson \& Litchfield, 2017). However, creativity is a driving force throughout the innovation journey. Its role in that journey is much more complex, diverse, and nuanced than implied by the conventional "division of labor" between the two concepts. First, creativity matters not only at the journey's outset, but also in resolving important challenges and resource needs throughout, e.g. when commercializing new products or services, or diffusing environmental or social innovations (e.g. Mumford 2002). To fulfil its complex role in processes of innovation, creativity demands ongoing efforts in organizing across what Perry-Smith and Manucci (2017: 53) have called the "idea journey", a concept that bridges the "macro approaches to innovation with micro approaches to creativity". Second, process studies of innovation have indicated that innovation processes are far less linear than commonly assumed by stage gate models (Van de Ven, 2017; Van de Ven, Polley, Garud, \& Venkataraman, 1999). Rather, the innovation journey involves complex temporalities (Garud, Gehman, \& Kumaraswamy, 2011) as well as multiple creative processes at different levels or related 
to different creative objects that are entangled with each other (Schiemer, Schüßler, \& Grabher, 2019), shifting our thinking away from linear towards recursive or conjunctive process models (Cloutier \& Langley, 2020).

By focusing on efforts of organizing creativity in the innovation journey, we seek to shed light on the organizing practices and processes unfolding in-between and connecting the behavioral microfoundations of creative individuals and groups on the one hand, and the institutional and economic macro processes related to creativity and innovation on the other. The focus on organizing creativity hereby adds nuances to how the innovation journey unfolds and allows theorizing the non-linear, sometimes even paradoxical dynamics inherent in most efforts to organize creative processes for innovation (Cohendet \& Simon, 2007; Lampel, Honig, \& Drori, 2014; Ortmann \& Sydow, 2018; Stjerne \& Svejenova, 2016; Townley \& Beech, 2010). For instance, rather than searching for an optimal "sweet spot" between organizational slack and structural constraints as a condition for creativity (e.g. Nohria \& Gulati, 1996), organizational research on creativity argues that resource limitations are socially constructed as either constraints or opportunities depending on organizational context conditions and practices of organizing (e.g. Rosso, 2014; Sonenshein, 2014). While important contributions have been made towards capturing social and organizational practices of engaging in, negotiating, and organizing creativity, more work is needed to advance the theoretical understanding, empirical insights, and methodological possibilities in researching creativity as a process of organizing that involves individuals and groups, yet is also embedded in the economic and institutional constraints of the innovation journey.

\section{FROM ORGANIZATIONAL TO ORGANIZING CREATIVITY}

Considered "a relatively unexplored area in organizational change and innovation" (Woodman et al., 1993: 293) in the early 1990s, organizational creativity is currently a diverse field of research spanning across levels of analysis: from the social context within organizations (e.g. Hargadon \& Bechky, 2006; Shalley \& Gilson, 2004), through social and interorganizational networks (e.g. De Vaan et al., 2015; Gilsing \& Duysters, 2008), to regional clusters and cities (e.g. Lange \& Schüßler, 2018; Cohendet, Grandadam, \& Simon, 2010), and organizational fields (e.g. Sgourev, 2013; Jones, Maoret, Massa, \& Svejenova, 2012). These contributions can be distinguished along two main - structural and practice perspectives. In recent years, process studies of creativity have become more prominent, suggesting a move from studies of organizational creativity, often following a variance ontology, to studies of organizing creativity as a practice and process (Fortwengel, Schüßler, \& Sydow, 2018). Below we briefly overview main tenets of the structural and practice perspectives before outlining the process perspective, which is central to our bringing together of the contributions to this volume.

Within the structural perspective, researchers have investigated the correlates of creativity with organizational structure, such as (de-)centralization, (in)formality or resource constraints (e.g. Cohendet \& Simon, 2007; Godart, Shipilov, \& Claes, 2014; Lampel et al., 2014). They have examined how organizational variables operate as a context to influence the creativity of individuals or groups (e.g. Moultrie \& Young, 2009; Woodman et al., 1993), thus either studying creativity in organizations, such as contextual factors influencing group processes (Sawyer, 2006), or organizational creativity, often understood as the 'fit' between structural factors of organizations and creative outputs. Network research has extended the organizational perspective on creativity to the structure of wider social and interorganizational networks (e.g. Burt, 2004; Cattani \& Ferriani, 2008; Fleming, Miongo, \& Chen, 2007; Obstfeld, 2005; Uzzi \& Spiro, 2005). This literature highlights how the position within networks influences the flow of information including the potential generation of novel and potentially valuable 
ideas, e.g. through brokers spanning across structural holes in social networks (e.g. Noyes, Allen \& Parise, 2012).

Within the practice perspective, research has focused on the interface between or, more precisely, the duality of structure and agency rather than attributing stability and routine to structure and ascribing creativity and change to agency. As Fortwengel et al. (2017: 5) underline, "the 'practice' view, understands creativity as a practised social process, in which structures play the important role of both enabling and constraining individual agents in pursuing creativity as a collective phenomenon". Practice theories allow overcoming a predominant dichotomous view that considers "too much" organization as impairing creativity and "too little" organization as undermining it (Chen, 2012). Thus, creativity and organization do not exist in opposition, but as mutually constitutive of each other. One example of such a practice-oriented study is Long Lingo and O'Mahony's (2010) analysis of brokerage practices among producers, labels, artists, and songwriters in Nashville's country music industry. From a practice perspective, actors do not 'disappear' from the analysis, but become contextualized through their roles and identities in the creative process.

In recent years, along with an overall interest in processes of organizational becoming and the emergence of novelty (Garud et al., 2015; 2016), a third - 'strong process' - perspective has gained prominence, moving research attention to "creativity as a constant flow of activity that crystallizes every once in a while in unpredictable moments of creativity" (Fortwengel et al., 2017: 5). Seeking to advance the understanding of creativity as processual, Håkonsen Coldevin and colleagues (2019) have noted the intertextuality of ideas, recognizing that they are not discrete or singular entities but, rather, develop in idea fields, a concept that overcomes the rather stylized and linear idea of the idea journey. Harvey (2014) sheds light on the collective process through which new ideas are developed by developing a dialectical model of creative synthesis as an outcome of multiple processes and interactions.

A process perspective allows us to better understand the intertwined processes of negotiations and interactions between members of the organization, and likely with external parties, that constitute the complex dynamics of organizing creativity in the innovation journey. For example, the idea journey unfolds in an ongoing tension between intentions and behaviors of ideators who seek to spark interest in an increasing number of allies and ensure the idea's organizational acceptance, and the vision, strategy, and expectations for the organization of its top management. As De Cock, Rehn, and Berry (2013) caution us, creativity as a "socio-economic good" is colonized by power relations and idea work itself requires acknowledging the role of co-optative power in the process of ongoing constitution and legitimating of ideas (Håkonsen Coldevin et al., 2019). A main consequence of this specific tension between the idea journey and strategic priorities is that it is difficult to isolate any linear sequence of stages. Furthermore, process studies help us to understand how organizational creativity is socially constructed and accomplished in a dual process of performing and attributing creativity (Koch et al., 2018), highlighting creativity as "located at the intersection of production and consumption - the two sides of the creative process competing for what should be seen as unexpected" (Godart, Seong, \& Phillips, 2020: 494).

A focus on organizing creativity as a process thereby also reveals the more invisible or suppressed aspects of what is "happening under so much active and activistic energy" in the pursuit of novelty (Rehn \& De Cock, 2009: 223). Such a critical stance can involve attention to 'creative deviance' (Mainemelis, 2010) or 'creative chaos' (Chen, 2009), opening up the black boxes (Cohendet \& Simon, 2015) or secret zones (Courpasson \& Younes, 2017) in which ideas develop. Furthermore, creative processes are fraught with time pressure, uncertainty, and ambivalence. These can be obstacles, but 
also enablers of creativity that can be harnessed as productive resources (e.g. Brinks et al., 2018). In sum, much is to be gained from unpacking both the idea journey and the contested idea work accompanying it.

\section{RESEARCH DIRECTIONS ON ORGANIZING CREATIVITY FOR INNOVATION}

The articles in this volume highlight how ideas are collectively constructed by organizational members and audiences through interactions that involve continuous feedback, conversations, and negotiations. These interactions aim at building shared understanding and vision, providing emotional and cognitive support, coping with and reducing uncertainty, as well as gaining influence and legitimacy for those involved in idea development and for the ideas themselves. Thus, far from being established in advance, the value and meaning of an idea is developed through a mosaic of perspectives, contributions, and revisions that help shape a complex set of interdependent options (Garud et al., 2013). Following repeated interactions, interlocking decisions eventually tighten this circle of possibilities and occasionally stabilize hypotheses about deliverables and models for creating value from the idea. A deep analysis of these interactions is key to the understanding of how and when a novel idea either successfully moves through the entire innovation journey or, rather, gets abandoned (prematurely or too late) in the process. The articles in this volume extend our understanding of organizing creativity in the innovation journey in four directions.

First, building on a longstanding tradition of creativity and innovation research in the context of cultural and artistic production (Jones, Svejenova, Strandgaard Pedersen, \& Townley, 2016; Lampel, Lant, \& Shamsie, 2000), three articles in our volume provide insights into the temporal dynamics of organizing creativity in artistic fields, applying a temporal and processual lens to cultural production and acknowledging the importance of entrainment in creative processes. The first two articles (Sgourev and Formilan, Cattani \& Feriani) focus on processes leading up to "consecration" of artistic work, whereas the third (Jones) investigates the role of arts festivals as central field conveners and how their organizing choices define which actors constitute the field in the first place. Together, these articles shed light on the creation, diffusion, and consecration of novel ideas and creative careers in artistic fields, thus providing a macro-perspective on organizing creativity for innovation.

Stoyan Sgourev's article "Inside Out: When Ideas from the Core Are Radicalized on the Periphery" posits a dynamic interface between core and periphery of artistic fields, whereby ideas appearing at the core are amplified on the periphery. He argues that quantitative and qualitative evidence from the history of art lend support to this argument, including breakthrough paintings such as "The Scream" by Munch and "Black Square" by Malevich. Conflicting theoretical perspectives present radical innovation as originating either from the core or the periphery of a system. Studies tend to bridge this divide by way of positions or roles. Inverting the established tendency of "tempering" of innovation from the periphery at the core, this article conceptualizes radicalization as a process of escalation of innovation in the form of sequences of ideas that originate at the center of a system and intensify at the periphery. In this perspective, the conditions favorable for the emergence of an idea may not be equally favorable for its radicalization, following a substantively different logic. This approach realigns the primacy of the core in diffusing ideas and that of the periphery in reinforcing distinctiveness.

The article "Trajectories of Consecration: Signature Style and the Pace of Category Spanning" by Giovanni Formilan, Gino Cattani, and Simone Ferriani provides a temporal perspective on the dynamics of distinctiveness and consecration in cultural production. The authors conceive of consecration as an emerging property of creative trajectories and distinguish signature style and pace of category spanning as main features for consecration. Using a social-sequence analytic approach, 
they examine the stylistic positioning in the discographies of a sample of 863 electronic music artists, seeking to capture the 'creativity rhythm' of their careers. They find that music artists with both specialist identities (those who adhere to a specific style over time) and eclectic identities (those who engage in spanning multiple categories, provided the spanning is fast paced) lead to distinctiveness and consecration as ultimate legitimation of artistic work. This article opens up opportunities for novel insights on how and when a signature style's coherence is appreciated by evaluators, and the importance of setting the right pace and rhythm to enable entrainment between what cultural producers do and how market expectations develop.

Candace Jones' article "Arts Festivals: Configuring Creative Fields through Temporal Strategies" compares the founding histories of the Berlin and Edinburgh arts festivals and pays particular attention to the temporal strategies used by the festival organizers and their different field-configuring outcomes. The empirical comparison of two festivals, founded roughly around the same time after World War II in different countries, reveals how the distinct spatial, cultural and material resources of each city shaped the festivals' imprints and trajectories in unique ways. The temporal strategies of the festivals are rather different. Whereas in Edinburgh all arts festivals are entrained, i.e. temporally aligned, with the Edinburgh International Festival, in Berlin the different arts festivals were sequential and less tightly coupled. As a result, Edinburgh has become a new center in the global arts field thanks to the intensity of the festival experience as well as the audience and media attention, whereas the Berlin festivals configured a more local creative field of artists and audiences. In sum, the study suggests that the temporality of arts festivals has different consequences for the structure of creative fields.

Second, three articles in our volume compare creative processes in arts and science, thereby elaborating on tensions and uncertainties in the creative process unfolding in different contexts and domains of creativity. Uncertainty about what is considered as novel and valuable can stem from the regulatory institutions surrounding creative processes such as employment systems or intellectual property regimes or from audiences in the creative process. Creative practices may involve the deliberate avoidance of contact with particular audiences as a means to reduce uncertainty stemming from evaluation (e.g. Svejenova, Mazza, \& Planellas, 2007), or may involve audiences such as consumers, critics or peers to get feedback on creative ideas or products at different stages of the creative process (Dempster, 2006). Together, these studies illuminate that what is considered as "novel" and "valuable" is highly contextualized and negotiated throughout the innovation journey.

The article "Auto-Tuned and R-Squared: Reflecting Audience Quality Evaluations in the Creative Process in Music Production and Cancer Research" by Elizabeth Long Lingo and Hille Bruns highlights how concerns about implementation - whether and how audiences might evaluate novel outcomes - infuse the collective creative process. For them, how audience quality evaluations shape the creative process remains largely unexplored. They examine this question through a comparative ethnography of two settings where big data brings audience quality evaluations to the fore-Nashville music production and systems biology cancer research. They find that actors encounter a fundamental tension between two competing standards of quality - the technically perfect, processed and ideal versus the empirically grounded, unprocessed and real—and show how actors navigate this tension vis-á-vis three different audiences: internal peers, extended community, and external reviewers. Based on ethnographic data, the authors illuminate the countless micro-decisions involved in producing a creative output, including considerations of audience evaluation, which plays a role throughout the creative process. 
Oliver Ibert, Gregory Jackson, Tobias Theel and Lukas Vogelgsang's article "Organizing Uncertainty as an Asset in Creative Collaboration: A Comparison of the Music and Pharmaceutical Industries" explores how uncertainty is organized as a productive resource in collaborative creativity aimed at the creation of novelty and sheds light on the trajectory of uncertainty in such processes. Drawing on eight creativity biographies (inspired by the innovation biography approach), four of music album production and four of pharmaceutical patent development, the authors reconstruct creative processes from idea generation to a tangible output, unraveling three distinct, yet interrelated practices for engaging with uncertainty - embracing, ignoring, and fixing - and revealing how these practices allow to continuously shift between uncertainty dimensions. Shifts in focal uncertainty help avoid blockage and re-contextualize previous knowledge. Further, the authors emphasize that only repeated shifts of focal and relegated uncertainty dimensions can sustain creative collaboration processes over time. They posit that it is through the collective engagement with uncertainty that creative collaboration generates novelty and ascribes value to newness.

The article "Between Anxiety and Hope? How Actors Experience Regulatory Uncertainty in Creative Processes in Music and Pharma" by Leonhard Dobusch, Konstantin Hondros, Sigrid Quack and Katharina Zangerle examines emotional-cognitive experiences of regulatory uncertainty as a prevailing, yet understudied feature of creative processes in the arts and sciences. Empirically, the study compares the two fields of music and pharma, both increasingly shaped by intellectual property rights. The interviews provide ample evidence that musicians, researchers, managers and legal professionals experience regulatory uncertainty surrounding intellectual property protection of prior creations not merely as a cognitive problem, but also as a trigger of emotions, ranging from indifference and doubt to anxiety and hope. The authors explain differences of emotional-cognitive experiences between professional actor groups with the feeling rules of the respective professions and propose to conceptualize emotional-cognitive experiences of regulatory uncertainty as a socially situated and relational phenomenon that reflects differences in socio-economic status and community membership.

Third, three articles in our volume discuss identity struggles of creative agents in organizations, thereby highlighting roles in creativity and innovation not only as a distinctive source and domain of expertise and even an occupation (Lam and also Rottem \& Oliver), but also as precarious (Round), given the inherent ambiguities in assessing creativity and the involved emotional demands. These contributions highlight how these agents - pracademics, innovation experts, employees in an advertising agency and university R\&D scientists - engage in identity work, while struggling with clashing roles and professional norms. The articles also point to a variety of ambiguities inherent in the processes of creativity and innovation, such as ambiguity in decision making, in measuring and evaluating what is creative and innovative, or in socialization, among others. They also capture some coping strategies that enable sustaining creative identities despite their contestation.

Alice Lam's article "Organizational Misfits as Creative Agents of Change: The Case of Pracademics" examines how identity dynamics marked by a 'misfit' between individuals' professional identities and work roles motivates a shift towards the development of positive identities. Following Mead (1934) and Joas (1996), Lam conceptualizes creative agency as the capacity to exercise imagination and choice, and enact new behaviors in response to problematic situations or interrupted contexts. Based on an empirical analysis of 'pracademics', experienced practitioners who have become academics, Lam unravels how when experiencing a 'misfit', these professionals liberate themselves from the limits of a particular identity through identity work. Through a 'hybridization' strategy, they partially alter their identities while seeking to influence their work contexts to achieve a better fit between their self-conceptions and external standards or role expectations, and through a 'positive distinctiveness' 
strategy they seek to communicate and affirm that difference or misfit is valuable. Through the creative agency of identity work, they can become 'transformative' change agents in organizations who redefine identity meanings, disrupt knowledge boundaries and initiate new work practices.

In the article "Ambiguous Zones and Identity Processes of Innovation Experts in Organizations, Rotem Rittblat and Amalya Oliver study innovation experts, a new occupation expected to produce orderly innovation processes to facilitate and integrate innovation in organizations. Based on interviews with 33 innovation experts in profit and nonprofit organizations, the authors analyze role expectations and identity processes. The study shows that these experts face different types of ambiguities: ambiguity in decision-making when strategic and operational levels are not aligned; in measuring innovation processes and their success in organizations; in socialization that makes it difficult to formulate a clear understanding of this field of expertise; in the dissonance between the desire to formalize the role of an innovation expert and existing organizational routines; and in the messages from the organizational environment. As a result, these experts find themselves navigating creatively through a 'fog' by gaining autonomy in building the role and defining their identity as mediators or entrepreneurs. By adopting these identities during the socialization process, they construct their role based on elements such as self-defined tasks, flexible knowledge base, detecting opportunities, interacting with colleagues and searching activities within the eco-system.

In her article "Creative Identity Work in the Face of Ambiguity: Defending, Distancing, Differentiating", Heather Round sets herself to examine the connection between creativity and identity in organizational settings. In particular, she delves into creative identity work amidst the precariousness and vagaries of creative assessment. She elaborates on the ambiguity inherent in such assessments, driven by changing contexts (e.g. geographical, cultural) and different (internal and external) judges which may lead to evaluation inconsistencies. Drawing on interviews and observations at two rather different sites of creativity - an R\&D laboratory and an advertising agency - Round finds that creative identity work unfolds in similar ways in these two settings, involving three strategies, namely defending, emotional distancing, and differentiating. These strategies enable individuals to maintain a coherent sense of self amidst ambiguity. However, they also involve personal struggles and emotional demands experienced. The study adds to the understanding of creativity as a socially constructed identity project, highlighting the precariousness of creativity roles, as well as the importance of a contextual perspective to capture it.

Fourth, a series of articles in this issue deals with the communicative journey of ideas from pitching to feedback, revealing how ideas are challenged, enriched and acquire meaning in communicative interaction. Communication is key to idea development since an idea requires a level of social exchange as well as acceptance and needs to be broadcasted to a wider audience in addition. While two articles (Parmentier, Le Loarne-Lemaire, \& Mellard and Hartmann, Koch, \& Wenzel) focus explicitly on the communicative interactions between idea developers and audiences and the role of feedback, one article (Nyfeler \& Hasse) problematizes the need for communicating novelty and surprise as superficial and potentially detrimental for innovation in core processes. Together, the articles show that the evaluation of an idea as creative does not depend on its intrinsic value, but on how and to whom it is communicated.

In their article "Do we really Judge the Book by its Cover? Idea Selection during Start-Up Weekends", Guy Parmentier, Severine Le Loarne-Lemaire and Maxime Mellard use a qualitative comparative approach when analyzing 57 pitches of entrepreneurial ideas during two start-up weekends. They show that proposing an idea whose content is new, feasible, and relevant is necessary for it to be selected by an audience, but not sufficient: the quality of the pitch, the appearance of the 
pitchers, their capacity to present the idea clearly, and their presence on stage is also a necessary condition for idea selection. The article questions the commonly shared assumption that the sole objective of a creative session is to generate as many ideas as possible. The principle behind this assumption is that the more ideas are generated, the more likely they are to include ones that are strong and of high quality. It is then up to the organization or the entrepreneur to select and exploit the best ideas. The article shows that the evaluation of an idea depends not only on its intrinsic value, but also on the context in which it is conducted and on the characteristics of those who present the idea.

In their article "Making Creativity, not Innovation. A Critical Reflection based on Observations from the Fashion Industry", Judith Nyfeler and Raimung Hasse take a critical view on the organized making of creativity, a process they call "creativization". Linking back to communicative approaches to creativity as a process of ascription (Koch et al., 2018; Godart et al., 2020), they suggest that creativity needs to be more clearly distinguished from innovation that is commonly the case. Whereas innovations need to be evaluated as improvements, creativity merely needs to be new and different from that which has already existed - as long as the difference comes as a surprise, which can be seen as the basis of value creation in the creative industries (Hutter, 2011). Based on this difference, and empirical data drawn from the fashion industry, Nyfeler and Hasse argue that the turn towards creativity actually comes at the expense of innovation, because a focus on constantly staging something as "novel" actually keeps the technological and knowledge core of an organization unchanged. This phenomenon, they argue, is common in sectors which focus on the permanent production of novelty, possibly including our own scientific community.

The article "Feedback on Creative Ideas: Toward a Communicative and Creative Action Perspective" by Michael Hartmann, Jochen Koch, and Matthias Wenzel extends the understanding of creative processes for innovation by introducing a theory of communicative and creative action aimed at unraveling the communicative interactions that may enable or hamper creativity. To articulate their perspective, the authors draw on the theory of communicative action by Jürgen Habermas and the theory on creative action by Hans Joas, making the case for a more complex and nuanced understanding of organizational creativity as constituted in communication processes whereby actors negotiate the novelty and usefulness of creative ideas. Hartmann and co-authors highlight the role of feedback interactions in shaping creative ideas. They also emphasize the importance of feedback givers as creative actors who struggle, use imagination, and engage in creative leaps when responding to creative endeavors, and of "spaces for play" as a communicative sphere, a "white canvas' that enables a tentative dialogical process for anticipating what might be. The conceptual arguments put forward are brought to life with illustrations from a Michelin-starred restaurant's communicative interactions in relation to creative ideas for a dish.

In addition to expanding the theoretical understanding of creative processes and practices along these four research directions, the articles also use new methodologies to advance an organizational perspective on creativity in the context of innovation, ranging from the QCA method (Parmentier et al.) to creative biographies (Ibert et al.) and social sequence analysis (Formilan et al.). Furthermore, several articles in this volume use comparative designs, situating or connecting creativity processes and practices and their dynamics in diverse contexts of innovation. These different contexts could present different segments of one field, e.g. Sgourev's examination of the radicalization of ideas from the core to the periphery, Formilan et al.'s equifinal trajectories to consecration for specialist and eclectic artists, or Jones' Berlin and Edinburgh art festivals with their different organizers, artists and audiences. The contexts to be compared can also span across fields. For instance, Ibert et al., Dobusch et al. as well as Long Lingo and Bruhns compare creativity in settings of arts and sciences, whereas Round compares creative identity work in an advertising agency and an R\&D lab. In these more 
micro-level studies, the challenges and tensions surfacing in the creative processes and the respective coping strategies were surprisingly similar. In both music production and cancer research, creative actors have to balance a tension between the ideal and the real (Long Lingo \& Bruhns). Similarly, intellectual property regulations trigger feelings of anxiety, indifference and hope in both the music and the pharma industry (Dobusch et al.). Rather than differences in industries or sectors, the articles in our volume thus point to differences among professional groups and roles within each sector or organization, indicating a need to situate studies of creative work in more than one comparative context.

\section{THEORETICAL IMPLICATIONS FOR RESEARCH ON ORGANIZING CREATIVITY FOR INNOVATION}

Building on the work of others who have developed elaborate process perspectives on innovation, the articles in this volume shed additional light on the messiness of the innovation journey, but also pinpoint important dimensions of organizing creativity which have theoretical implications and, thereby, open up avenues for further research. Below we suggest several fruitful directions.

First, we encourage research that expands the meaning of creative actor to account for multiple creative actors' contributions to creativity in the innovation journey: audiences at an entrepreneurial pitch, legal professionals, professional 'innovation experts', peers, event organizers as well as reviewers and other evaluators. While some of these are more at the core of creative processes and others more at the periphery, they all "work" with ideas in one way or other. This collective creative agency comes in "spaces for play" (Hartmann et al.) and involves multiple forms of interactions: communicating, identity work, staging and convening, radicalizing and tempering, mediating and giving feedback, engaging with uncertainty, dealing with emotions or judging and evaluating. All of these matter in the process of creation - not necessarily in a clear-cut "stage" or "phase", but via anticipation and feedback throughout the innovation journey.

Second, we propose to engage further in (de)constructing the notion of creativity, particularly its common definition as "novel" and "useful". As problematized in previous work (Rehn and De Cock, 2009) and further interrogated the chapter by Nyfeler and Hasse, this definition actually blurs the line to innovation in a way that makes us overlook how a focus on novelty creation might actually come at the expense of useful innovation. This might be particularly salient in contexts where fashion plays a role - in the fashion industry itself, but also beyond it. Godart et al. (2020) already argued that the contested and political nature of evaluation is more important to sociological research on creativity than the focus on "usefulness". The articles in this volume inspire us to think further about the multiple and possibly conflicting criteria for evaluating creativity. For instance, in idea pitches, feasibility of the project or the capabilities of the pitchers themselves play an important role (Parmentier et al.). In both artistic and scientific fields, the technically perfect, processed and ideal versus the empirically grounded, unprocessed and real constitute two competing standards of quality (Long Lingo \& Bruhns). Further research, particularly from a process perspective, could unpack how the notion of creativity itself is shaped and molded in the process of creating by different actors and through different practices of creative work.

Third, we appeal to continue situating research on creativity and innovation. As the articles in this volume have shown, what different actors involved in the creative process do, what they value and define as creative varies by context, as do the challenges of organizing creativity. In addition to comparing arts and science, further research could compare "injected creativity" in established contexts with entrepreneurial contexts, or profit-driven versus nonprofit-driven forms. Here the chapters in this volume indicate the importance of the macro context in which creativity is embedded, 
moving us far away from the original psychological approach towards studying regulatory structures, field-level processes and professional groups and their role in shaping the creative process.

Furthermore, organizing creativity happens not just in the innovation journey, but matters in other contexts such as activism, social innovation, or civic creativity, all of which could be considered further by comparative, multi-level research on organizing creativity.

Fourth, several articles in this volume provided a temporal perspective on organizing creativity and highlighted the importance of creative trajectories, pace, rhythms, and entrainment in understanding creativity at the field level (e.g. Sgourev; Formilan et al.; Jones). Further work could build on these and previous contributions (e.g. Garud, Gehman, \& Kumaraswamy, 2011; Ortmann \& Sydow, 2018; Stjerne \& Svejenova, 2016) to advance and expand not only a temporal, but also a temporality perspective on organizing creativity for innovation, investigating the complex relationship between past, present, and future. Hernes, Feddersen, and Schultz (2021: 354) clarify that whereas "“time' signals a resource that may be expressed as a universal, objective measure", "temporality signals that the time in question belongs exclusively to the entity". They show the importance of temporality for innovation processes by examining how a Danish beer company sought to re-brew yeast from 1880s' bottles, reimagining the past into the future. Attention to temporality could open up new questions on struggles and opportunities involved in creative and innovation processes in time, and not only over time.

Last, all contributions in this volume refer to a benevolent form of creativity. However, it is also important to not overlook or ignore the dark, hidden, and secretive sides of creativity. Cropley, Kaufman, and Cropley (2008), for example, draw a distinction between malevolent creativity creativity that is deliberately planned to damage others - and earlier conceptions of the dark side of creativity that consider only negative concepts of creativity, that is, unintentionally bad outcomes. Further empirical, theoretical, and methodological contributions are needed to study processes of negative creativity that acknowledge the possibility of harmful outcomes in the production of novelty from a critical perspective. It is hereby important to stay attentive to potential blind spots or repressed areas in understanding creative processes. For example, future research may critically examine property rights and organizing of and capitalizing on creativity, not only for economically powerful corporations but also for those actually involved in the creation and development of creative work.

\section{References}

Amabile, T. M. (1996). Creativity in context. Boulder, CO: Westview Press.

Amabile, T. M. (1988). A model of creativity and innovation in organizations. Research in Organizational Behavior, 10, 123-67.

Anderson, N., Potočnik, K., \& Zhou, J. (2014). Innovation and creativity in organizations: A state-ofthe-science review, prospective commentary, and guiding framework. Journal of Management, 40(5), 1297-1333.

Burt, R. S. (2004). Structural holes and good ideas. American Journal of Sociology, 110, 349-399

Brinks, V., Ibert, O., Müller, F. C., \& Schmidt, S. (2018). From ignorance to innovation: Serendipitous and purposeful mobility in creative processes-The cases of biotechnology, legal services and board games. Environment and Planning A: Economy and Space, 50(8), 1742-1763.

Cattani, G., \& Ferriani, S. (2008). A core/periphery perspective on individual creative performance: Social networks and cinematic achievements in the Hollywood film industry. Organization Science, 19 (6), 824-844. 
Chen, K. K. (2012). Organizing creativity: Enabling creative output, process, and organizing practices. Sociology Compass, 6(8), 624-643.

Chen, K. K. (2009). Enabling creative chaos: The organization behind the Burning Man event. Chicago, USA: University of Chicago Press.

Cloutier, C., \& Langley, A. (2020). What makes a process theoretical contribution? Organization Theory, 1(1), in print.

Cohendet, P., \& Simon, L. (2015). Introduction to the special issue on creativity in innovation. Technology Innovation Management Review, 5(7), 5-13.Cohendet, P., Grandadam, D., \& Simon, L. (2010). The anatomy of the creative city. Industry and Innovation, 17(1), 91-111.

Cohendet, P., \& Simon, L. (2007). Playing across the playground: Paradoxes of knowledge creation in the videogame firm. Journal of Organizational Behavior, 28(5), 587-605.

Courpasson, D., \& Younes, D (2017). Double or quits: Understanding the links between secrecy and creativity in a project development process. Organization Studies, 39(2-3), 271-295.

Cropley, D. H., Kaufman, J. C., \& Cropley, A. J. (2008). Malevolent creativity: A functional model of creativity in terrorism and crime. Creativity Research Journal, 20(2), 105-115.

De Cock, C., Rehn A., \& Berry, D. (2013). For a critical creativity: The radical imagination of Cornelius Castoriadis. In J. Chan \& K. Thomas (Eds.), Handbook of research on creativity (pp. 150-161). Cheltenham, UK: Edward Elgar.

DeFillippi, R., Grabher, G., \& Jones, C. (2007) Introduction to paradoxes of creativity: Managerial and organizational challenges in the cultural industries. Journal of Organizational Behavior, 28, 511521.

Dempster, A. M. (2006) Managing uncertainty in creative industries: Lessons from Jerry Springer the opera. Creativity and Innovation Management, 15(3), 224-233.

De Vaan, M., Stark, D., \& Vedres, B. (2015). Game changer: The topology of creativity. American Journal of Sociology, 120(4), 1144-1194.

Fleming, L. Miongo, S., \& Chen, D. (2007) Collaborative brokerage, generative creativity, and creative success. Administrative Science Quarterly, 52, 443-475.

Fortwengel, J., Schüßler, E., \& Sydow, J. (2017). Studying organizational creativity as process: Fluidity or duality? Creativity and Innovation Management, 26(1), 5-16.

Galenson, D. W. (2007). And now for something completely different: The versatility of conceptual innovators. Historical Methods: A Journal of Quantitative and Interdisciplinary History, 40(1), $17-27$.

Garud, R., Gehman, J., Kumaraswamy, A., \& Tuertscher, P. (2016). From the process of innovation to innovation as process. In A. Langley \& H. Tsoukas (Eds.), The SAGE handbook of process organization studies (pp. 451-466). London: Sage.

Garud, R., Simpson, B., Langley, A., \& Tsoukas, H. (Eds.) (2015). The emergence of novelty in organizations. Oxford: Oxford University Press.

Garud, R., Tuertscher, P., \& Van de Ven, A. H. (2013). Perspectives on innovation processes. Academy of Management Annals, 7(1), 775-819.

Garud, R., Gehman, J., \& Kumaraswamy, A. (2011). Complexity arrangements for sustained innovation: Lessons from 3M Corporation. Organization Studies, 32(6), 737-767.

George, J.M. (2007). Creativity in organizations. Annals of the Academy of Management, 1: 439-477.

Gilson, L.L. \& Robert C. Litchfield (2017). Idea collections: A link between creativity and innovation. Innovation, 19(1), 80-85.

Gilsing, V. A., \& Duysters, G. M. (2008). Understanding novelty creation in exploration networksstructural and relational embeddedness jointly considered. Technovation, 28(10), 693-708.

Godart, F., Seong, S., \& Phillips, D. (2020). The sociology of creativity: Elements, structures, and audiences. Annual Review of Sociology, 46, 489-510.

Godart, F.C., Shipilov, A.V., \& Claes, K. (2014) Making the most of the revolving door: The impact of outward personnel mobility networks on organizational creativity. Organization Science, 25(2), $377-400$.

Håkonsen Coldevin, G., Carlsen, A., Clegg, S., Pitsis, T.S., \& Antonacopoulou, E.P. (2019). Organizational creativity as idea work: Intertextual placing and legitimating imaginings in media development and oil exploration. Human Relations, 72(8), 1369-1397. 
Hargadon, A.B., \& Bechky, B.A. (2006). When collections of creatives become creative collectivities: A field study of problem solving at work. Organization Science, 17, 484-500.

Harvey, S. (2014). Creative synthesis: Exploring the process of extraordinary group creativity. Academy of Management Review, 39(3), 324-343.

Hennessey B.A., \& Amabile, T.M. (2010). Creativity. Annual Review of Psychology, 61, 569-98.

Hernes, T., Feddersen, J., \& Schultz, M. (2021). Material Temporality: How materiality 'does' time in food organizing. Organization Studies. 42(2), 351-371.

Hutter, M. (2011). Infinite surprises: on the stabilization of value in the creative industries. The worth of goods. In J. Beckert \& P. Aspers (Eds.), The worth of goods. Valuation and pricing in the economy (pp. 201-220). Oxford: Oxford University Press.

Joas, H. (1996). The creativity of action. Chicago: University of Chicago Press.

Jones, C., Maoret, M., Massa, F. G., \& Svejenova, S. (2012). Rebels with a cause: Formation, contestation, and expansion of the de novo category "modern architecture," 1870-1975. Organization Science, 23(6), 1523-1545.

Jones, C., Svejenova, S., Strandgaard Pedersen, J, \& Townley, B. (2016). Misfits, Mavericks and Mainstreams: Drivers of Innovation in the Creative Industries. Organization Studies, 37(6), 751768.

Koch, J., Wenzel, M., Senf, N. N., \& Maibier, C. (2018). Organizational creativity as an attributional process: The case of haute cuisine. Organization Studies, 39(2-3), 251-270.

Lampel, J., Lant, T., \& Shamsie, J. (2000) Balancing act: Learning from organizing practices in cultural industries. Organization Science, 11, 263-269.

Lampel, J., Honig, B., \& Drori, I. (2014). Organizational ingenuity: Concept, processes and strategies. Organization Studies, 35(4), 465-482.

Lange, B., \& Schüßler, E. (2018). Unpacking the middleground of creative cities: spatiotemporal dynamics in the configuration of the Berlin design field. Regional Studies, 52(11), 1548-1558.

Lingo, E. L., \& O'Mahony, S. (2010). Nexus work: Brokerage on creative projects. Administrative Science Quarterly, 55(1), 47-81.

Mainemelis, C. (2010). Stealing fire: Creative deviance in the evolution of new ideas. Academy of Management Review, 35(4), 558-578

Mann, L., \& Chan, J. (Eds.). (2011). Creativity and innovation in business and beyond: Social science perspectives and policy implications. New York, NJ: Routledge.

Mead, G. H. (1934). Mind, self and society. Chicago, IL: University of Chicago Press.

Menger P-M. (2014). The economics of creativity: Art and achievement under uncertainty. Cambridge, MA: Harvard University Press

Mumford, M. D. (2002). Social innovation: Ten cases from Benjamin Franklin. Creativity Research Journal, 14(2), 253-266.

Moultrie, J., \& Young, A. (2009) Exploratory study of organizational creativity in creative organizations. Creativity \& Innovation Management, 18(4), 299-314.

Nohria, N., \& Gulati, R. (1996). Is slack good or bad for innovation? Academy of Management Journal, 39(5), 1245-1264.

Noyes, E., Allen, I. E., \& Parise, S. (2012). Innovation and entrepreneurial behaviour in the Popular Music Industry. Creative Industries Journal, 5(1-2), 139-150.

Obstfeld, D. (2005). Social networks, the tertius jungens orientation and involvement in innovation. Administrative Science Quarterly, 50, 100-130.

Ortmann, G. \& Sydow, J. (2018). Dancing in chains: Creative practices in/of organizations. Organization Studies, 39(7), 899-921.

Perry-Smith, J. E., \& Mannucci, P. V. (2017). From creativity to innovation: The social network drivers of the four phases of the idea journey. Academy of Management Review, 42(1), 53-79.

Reckwitz, A. (2017). The invention of creativity: Modern society and the culture of the new. Cambridge, UK: Polity Press.

Rehn, A. \& De Cock, C. (2009). Deconstructing creativity. In T. Rickards, M. Runco \& S. Moger (Eds.), The Routledge companion to creativity (pp. 222-231). Milton Park: Routledge.

Rosso, B. D. (2014). Creativity and constraints: Exploring the role of constraints in the creative processes of research and development teams. Organization Studies, 35(4), 551-585. 
Sawyer, R. K. (2006). Group creativity: Musical performance and collaboration. Psychology of Music, $34(2), 148-165$.

Schiemer, B., Schüßler, E., \& Grabher, G. (2019). Collaborative innovation online: Entanglements of the making of content, skills, and community on a songwriting platform. Research in the Sociology of Organizations, 64, 293-316.

Sgourev, S. V. (2013). How Paris gave rise to Cubism (and Picasso): Ambiguity and fragmentation in radical innovation. Organization Science, 24, 1601-1617.

Shalley, C. E., \& Gilson, L. L. (2004). What leaders need to know: A review of social and contextual factors that can foster or hinder creativity. The Leadership Quarterly, 15(1), 33-53.

Sonenshein, S. (2014). How organizations foster the creative use of resources. Academy of Management Journal, 57(3), 814-848.

Stjerne, I.S., \& Svejenova, S. (2016). Connecting temporary and permanent organizing: Tensions and boundary work in a series of film projects. Organization Studies, 37(12), 1771-1792.

Svejenova, S., Mazza, C., \& Planellas, M. (2007) Cooking up change in haute cuisine: Ferran Adrià as an institutional entrepreneur. Journal of Organizational Behavior, 28(5), 539-561.

Townley, B., \& Beech, N. (2010). (Eds.) Managing creativity: Exploring the paradox. Cambridge: Cambridge University Press.

Uzzi, B., \& Spiro, J. (2005). Collaboration and creativity: The small world problem. American Journal of Sociology, 111(2), 447-504.

Van de Ven, A.H. (2017). The innovation journey: you can't control it, but you can learn to maneuver it. Innovation, 19(1), 39-42.

Van de Ven, A. H., Polley, D. E., Garud, R., \& Venkataraman, S. (1999). The innovation journey. New York, NY: Oxford University Press.

Woodman, R., Sawyer, R., \& Griffin, R. (1993). Toward a theory of organizational creativity. Academy of Management Review, 18 (2), 293-321. 